\title{
Agent-Based Modeling for Studying the Impact of Capacity Mechanisms on Generation Expansion in Liberalized Electricity Market
}

\begin{abstract}
N.Y Dahlan ${ }^{\dagger}$
Abstract - This paper presents an approach to solve the long-term generation expansion planning problem of the restructured electricity industry using an agent-based environment. The proposed model simulates the generation investment decisions taken by a particular agent (i.e. a generating company) in a market environment taking into account its competitors' strategic investment. The investment decision of a particular company is modeled taking into account that such company has imperfect foresight on the future system development hence electricity prices. The delay in the construction of new plants is also explicitly modeled, in order to compute accurately the yearly revenues of each agent. On top of a conventional energy market, several capacity incentive mechanisms including capacity payment and capacity market are simulated, so as to assess their impact on the investment promotion for generation expansion. Results provide insight on the investment cycles as well as dynamic system behavior of long-term generation expansion planning in a competitive electricity industry.
\end{abstract}

Keywords: Agent-based modeling, Generation expansion planning, Energy-only market, Capacity payment, Capacity market, Liberalized electricity market

\section{Introduction}

Generation expansion in a competitive electricity market is a complex process, whose optimal outcomes are sensitive to what each of its players might decide to invest on, in the short and long run. The traditional generation expansion planning (GEP) problem, which was solved in a central manner, has been replaced by individual profit maximizations problems, in which perfect information is not available. In this uncertain environment, the generating company (GenCo) must rely on forecasts for fuel and demand, as well as their own judgment to anticipate what investment strategies its competitors might choose; in order to determine its own best investment decisions as well as optimal market bidding.

Two main techniques have been used to model generation investment activities in liberalized electricity market, 1) Game theory and 2) System Dynamics. Although game theory has been extensively used in the literature [1-7] the problem of dimensionality for $\mathrm{N}$-player applications is still a major barrier for its widespread adoption [8]. System Dynamics (SD) is based on top-down approach where the outside view of the system generation expansion is first presented and causal relationship is used to model the interactions between the participants in the market [9-11]. However, in such techniques, the fundamental process of how the companies assess the investment is not presented in detail, and this could have serious implications on the

\footnotetext{
$\dagger \quad$ Corresponding Author: Faculty of Electrical Engineering, Universiti Teknologi MARA (UiTM), Shah Alam, Selangor, Malaysia. (nofriyenita012@ppinang.uitm.edu.my)
}

Received: May 26, 2014; Accepted: March 18, 2015 simulation outcomes. Agent-based modeling (ABM), on the other hand, can handle large numbers of players, and the detail of how the companies take decisions is not limited. As opposed to SD, ABM uses a bottom-up approach in which the individual elements of the system are first defined in an explicit way and then linked together to form a larger system. In ABM, each agent assesses its situation in the environment and makes decisions to achieve its target using a predefined set of rules. In GEP, the agents are GenCos who are seeking to maximize their own profits over the whole optimization horizon, taking into account the potential decisions of its competitors. Furthermore, in liberalized electricity markets, the GenCos lack of perfect foresight of fuel prices and load growth, as well as delays in construction and permit approval for the chosen investment plants could result in unstable dynamics in capacity investments $[12,13]$. Using ABM the aspects that contribute to the 'boom' and 'bust' patterns of investment cycles can be incorporated in the generation expansion model. By being able to simulate these cycles, the potential investments risks to each of the GenCos could be better assed and hedged, if desired. Also, the potential risk of having capacity shortage, could be identified well in advance. In order to avoid such capacity shortages, some regulatory authorities have imposed capacity mechanisms to stabilize system reserves and to provide GenCos an opportunity to earn extra revenue while enhancing the system adequacy.

This paper proposes ABM for long-term GEP considering imperfect foresight of the GenCo in making investment decision as well as incorporating the construction delays of the new plants. Energy-only market and two types of 
capacity mechanisms i.e. 1) capacity payment and 2) capacity market are explicitly presented and tested using the proposed agent-based generation expansion model. The impact of these mechanisms on the investment choice of the GenCos and the dynamic system behavior of long-term generation expansion are presented.

This paper is organized as follows. In section 2 we first describe the concept of ABM. Section 3 explains the application of ABM in electricity market. Section 4 describes the proposed GEP model using ABM. This includes the overview of the model, electricity market design, competitors' investment strategy and decision making. In section 5, we explain the capacity expansion mechanism. In section 6 we discuss the test results considering four different case studies. Finally, in section 7 we draw some conclusions.

\section{Concept of Agent-Based Modeling (ABM)}

In ABM, a system is represented as a collection of autonomous agents who individually assess their situation in an environment and make decisions using a set of decision rules. Each agent has the capability to learn and adapt to its environment in a social, communicative and intelligent way to achieve its target. ABM repetitively simulates the decision process and the interactions of the agents and can thus be used to study the dynamics of complex systems.

A spread sheet or mathematical software such as Mathematica or MatLab can be used to develop ABM; however with those tools the applications can only represent a small number of agents [30]. Large-scale agent models are usually developed using specialized agent simulation environments such as Repast, Swarm and NetLogo. These environments support several features useful to agent modelers including the provision of communication mechanisms, various agent architectures and flexible interaction topologies. It is beyond the scope of this paper to use a sophisticated agent-based environment to develop an agent-based generation expansion model. Instead, the agent-based GEP model in this paper was developed using MatLab software.

\section{Application of ABM in Liberalized Electricity Market}

ABM has been widely applied in modeling activities in the liberalized electricity market. Bower and Bunn [14] were the first to use agent-based modeling to represent electricity trading. They applied the technique to compare the Electricity Pool of England and Wales with the New Electricity Trading Arrangement (NETA). Bunn and Oliveira [15] presented the first detailed study of the relationship between bilateral trading and the balancing market in
NETA. Bunn and Martoccia [16] analyzed generator market power in the Electricity Pool of England and Wales. Other papers that used ABM to study bidding strategy and coalition in electricity market are presented by [17-19]. A study by [20] developed an Agent-based Modeling of Electricity Supply (AMES) using Repast to model the wholesale electricity market run by the New England Independent System Operator and the Midwest Independent System Operator (MISO). More general electricity market simulators, EMCAS [21] and MASCEM [22] also use ABM approaches to simulate the operation of other electricity markets. Bagnall and Smith focus on improving GenCos' decision in UK electricity market through learning [23] and agent architecture [24]. The application of ABM has been recently extended to consider uncertainty in wind generation [25] and demand response in electricity market [26].

However, only a few works use ABM for modeling long-term GEP in liberalized markets. These works include [27-29]. The GEP developed by [27] is composed by two main stages: 1) a stage in which each GenCo forecasts the expected profit of its investment and 2) a stage in which the actual market clears after all the companies have made their investment decisions. However, in this model the capacity mechanisms to promote generation expansion and their impacts on the system's adequacy are not considered in the analysis. On the other hand, the model presented in [28] analyses the effect of capacity mechanisms on the investment decision of the GenCos; however, the authors do not consider the effect of investment decisions by all the GenCos on the actual market and system expansion. The work by [29] uses a complex Electricity Market Multi-Agent System (EMMAS) to simulate electricity spot market. However, the optimal GEP is for a single company to maximize profit and solved using Dynamic Programming (DP) technique. The Generation Expansion Multi-Agent based model proposed in this study considers the two elements that was not taken into account in the literature [27-29], i.e. i) capacity incentive mechanisms within the agent-based generation expansion framework and ii) the impact of capacity mechanisms on the overall system generation expansion.

\section{Proposed Model for Generation Expansion Planning Using Agent-Based Modeling}

\subsection{Overview of the proposed model}

Fig. 1 shows the proposed framework of GEP using ABM. In this approach, the GenCo is modeled as an independent agent who reacts through a market (i.e. its environment) to maximize its profits. In general, the agents take decision following two main stages: 1) forecasting stage, 2) actual market clearing stage. In the forecasting stage, while evaluating an investment plant, each GenCo 
forecasts the future load growth, the fuel costs and the potential competitors' investment strategy. Using these values, the GenCo calculates the expected energy prices by simulating the market clearing on a yearly basis, and then estimates the revenue of each of its generating plants in its portfolio over their lifetime. In order to establish its forecast, it is assumed that each GenCo has access to initial system information such as current load, system capacity, fuel costs and system wide reserve requirements. If the GenCo evaluates more than one possible plant for expansion, it will compare the profit of the different investment options and choose to build the most profitable one. In this model, it is assumed that the generating companies make expansion decisions on a yearly basis.

After all the GenCos have decided on the expansion plants to invest in a particular year (if any), the actual market clearing is performed based on the actual system quantities (fuel costs, load, etc.) and new entrant generating capacity (if the construction time has been completed). Here, the actual system developments and electricity prices may deviate from the GenCos' expectations in the forecasting stage. The new power plants chosen by each GenCo that have a longer construction time, enter the system only after their construction has been completed. The actual market model is used to calculate the actual energy prices in the current year. Finally, at the end of each year, the model updates the new system information regarding the load, capacity additions and capacity retirements. The generating companies then use this information to make decisions about the next round of investments the following year. In this model, all the generating companies use a similar investment evaluation model to make a decision on a new investment. However, while making expansion decisions, each GenCo also takes

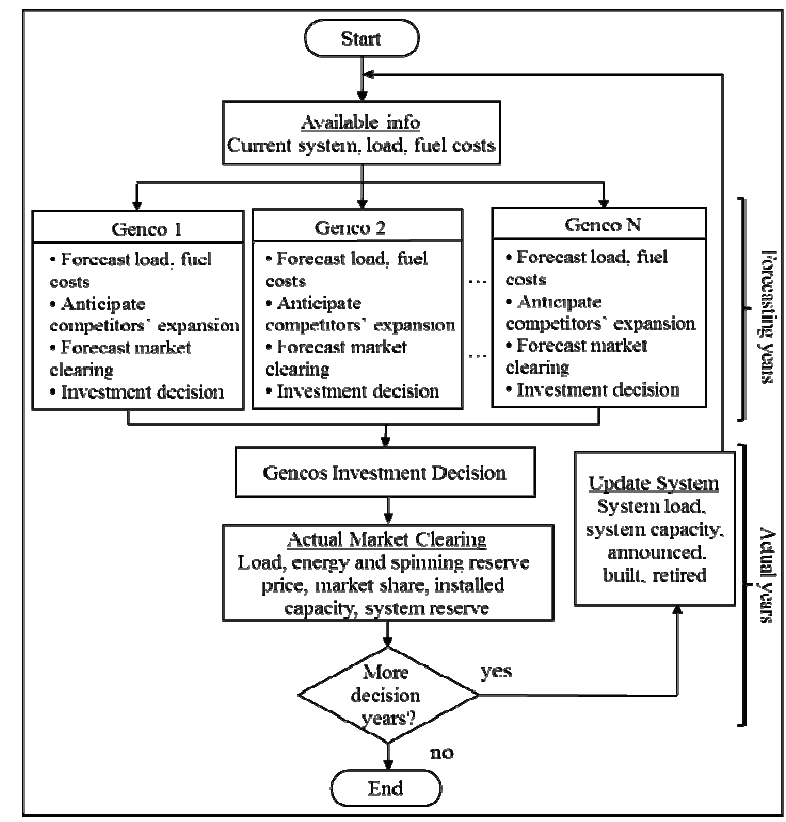

Fig. 1. Framework of GEP using agent-based modeling into account the effect of a new investment on the profitability of its existing portfolio. Since each GenCo has a different generating portfolio, they may come out with different investment strategies to maximize their overall profit. This process is illustrated in Fig. 1.

\subsection{Electricity market design}

The market model simultaneously clears the energy and spinning reserve markets, for each segment of the discretized load duration curve (LDC) of each year. The market clearing process is modeled as an optimization problem in which the total yearly operating cost is minimized:

$$
\min \left\{\sum_{s=1}^{S} \sum_{i=1}^{I}\left(M C b_{i} p_{i, s} d_{s}\right)\right\}
$$

where $S$ is the number of segments in the LDC, $I$ is the number of units participating in the market, $M C b_{i}$ is the bidding price of generating unit $i, p_{i, s}$ is the power produced by generating unit $i$ at segment $s$ and $d_{s}$ is the duration in hours of segment $s$. The optimization is subject to power balance, reserve requirements and minimum and maximum stable generation of the units as follows:

$$
\begin{gathered}
\sum_{i=1}^{I} p_{i, s}=p d_{s} \quad \forall s \in S \\
\sum_{i=1}^{I} r_{i, s} \geq r d_{s} \quad \forall s \in S \\
\delta_{i, S} P_{i}^{\text {min }} \leq p_{i, s} \leq \delta_{i, s} P_{i}^{\text {max }}
\end{gathered}
$$

where $\delta_{\mathrm{i}, \mathrm{s}}$ is a binary variable $\delta_{\mathrm{i}, \mathrm{s}} \in\{0,1\}$, that determines the status of generating unit $i$ at segment $s, p d_{s}$ is the system wide demand for segment $s$ of the LDC and $r d_{s}$ is the system's spinning reserve requirement.

The model assumes that each company bids at a price that covers both its variable and quasi-fixed production costs [28] to produce electrical energy as follows:

$$
M C b_{i}=f_{c} m_{i}+\frac{f_{c} b_{i}}{P_{i}^{\min }}
$$

where $m_{i}$ is the slope of the linearized input-output characteristic of generating unit $i$ (MBTU/MWh), $b_{i}$ is the $y$-offset of the linearized input-output characteristic of generating unit $i(\mathrm{MBTU} / \mathrm{h}), f_{c}$ is the fuel cost $(\$ / \mathrm{MBTU})$ and $P_{i}^{\min }$ is the minimum generation of unit $i$ (MW).

In this model it is assumed that there are no separate bids for the provision of spinning reserve in the market. Instead, the generating units providing this service is paid the opportunity cost of selling the otherwise generated energy in the energy market. This assumption is reasonable if the generators do not incur a direct cost when providing 
reserve. However, in reality there are some costs that generators must bear when they provide reserve such as the additional maintenance cost for providing reserve.

\subsection{Anticipating competitors' investment decision}

The anticipated investments from other competitors in each decision year are modeled using a scenario tree. The representation of each competitor's investment scenario consists of investment options; that is, a list of expected new power plants that might be chosen by the competitor. It is assumed that since all the generating companies are in the same business, they can make an educated guess about their competitors' investment options. Since investing in power generation requires large investments, it is also assumed that the competitors only choose to build a single plant each year. In the resulting scenario tree structure each layer represents the investment options that each competitor has. The probabilities of selecting the options are specified individually for each competitor over the layers of the scenario trees. This is shown graphically in Fig. 2 where GenCo 1 is evaluating an investment and GenCo 2, GenCo 3 and others are its competitors. Once all the competitors' investment scenarios are defined and the probability of each scenario is determined, electricity prices and revenues of the new plant under evaluation are calculated for each scenario's realization over all leaves in the scenario trees. The average expected revenue of the new plant is then computed considering all the scenarios of competitors' investment strategy. By using this technique the generating companies are able to consider all the possible investments that might be taken by the competitors while evaluating their investment.

\subsection{Decision making process}

Decision making process consists of determining which

Competitors' investment expectation

Genco 1

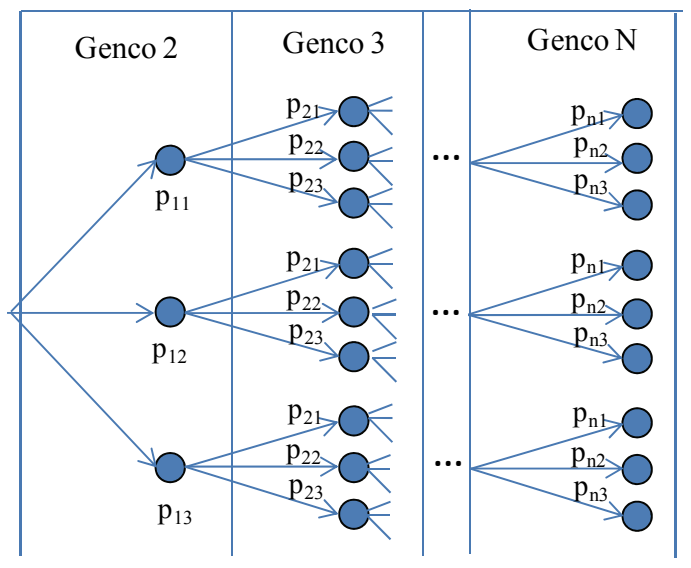

Expected power plant for expansion

Fig. 2. Scenario trees of competitors' investment investment option is the most profitable. To estimate the profit, the GenCo must first acquire the expected revenue and the cost of each plant. This is done by clearing the market for each year of the plant's lifetime. The net revenue of each GenCo is then computed using the following equation:

$$
P_{\mathrm{GenCo}}=\sum_{\forall j \in J}\left(E R_{j}+S R_{j}-P C_{j}\right)
$$

where $J$ is the set of generating units that belong to a given GenCo, $E R_{j}$ is the yearly revenue from the energy market, $S R_{j}$ is the yearly revenue from providing spinning reserve and $P C_{j}$ is the production cost of unit $j$.

The yearly energy revenues, revenues from providing spinning reserve and production cost are given as:

$$
\begin{gathered}
E R_{j}=\sum_{s=1}^{S} \pi_{\text {clear }, s} P_{j, s} d_{s} \\
S R_{j}=\sum_{S=1}^{S}\left(\pi_{\text {clear }}-M C B_{j}\right)\left(P_{j}^{\text {max }}-p_{j}\right) d_{s} \\
P C_{j}=\sum_{s=1}^{S}\left(f_{c} m_{j}+\frac{f_{c} b_{j}}{p_{j, s}}\right) p_{j, s} d_{s}
\end{gathered}
$$

where $\pi_{\mathrm{clear}, s}$ is the market clearing prices for energy at segment $s$ of the LDC.

Once the revenues and costs have been computed for each year of the lifetime of a given possible expansion plant and the initial investment is assumed to be paid uniformly throughout the building time, the Future Worth Value (FWV) at a Minimum Acceptable Rate of Return (MARR), and the Internal Rate of Return (IRR) of the generated cash-flow is calculated.

If a given GenCo is evaluating more than one expansion plants, the selected plant must have positive FWV and IRR higher than MARR. If more than one plant has IRR greater than MARR, the one with the greater FWV is selected. If more than one plant meets these criteria, then the one with the higher expected increment on the overall profits is selected. On the other hand, if none of the plants meets these criteria, the GenCo chooses not to build anything in that year.

\section{Capacity Expansion Mechanisms}

Various capacity mechanisms have been proposed over the last two decades. Among these the most one can find are: 1) capacity payment which had been implemented under the old Electricity Pool of England and Wales and still exist in Spain and several Latin American countries, and 2) capacity markets which have been adopted in the north east of the United States. Some studies have been conducted to study and compare the effectiveness of several capacity mechanisms in a qualitative way [31-33]. 
The authors of [34] quantitatively study the dynamic capacity payment applied in the old power pool of England and Wales. The investment model is developed using System Dynamics. The author of [12] also uses System Dynamics to simulate the construction cycles of power generation in the western United States. [35] presents a dynamic simulations model in evaluating the performance of three market designs i.e. energy-only market, capacity payment and capacity market. A simple dynamic model that could represent the effects of the demand curve for PJM Reliability Pricing Model (RPM) on the reserve margin, generator profitability and consumer cost are presented in [36, 37]. A single representative agent is used in the model. However, none of the works describe above explicitly presents the capacity mechanisms within GEP model using $\mathrm{ABM}$ and study the impact of capacity mechanisms on the investment decision of generating companies and overall system expansion. This is considered in the proposed model presented in this paper.

The model has been tested considering the electricity market works as energy-only market, and with two different expansion mechanisms: 1) capacity payments and 2) capacity markets.

\subsection{Energy-only markets}

In these markets, the generators submit their bid and all the bids below the market clearing price are dispatched and paid the market clearing price. The revenues of the generators come from selling energy and procuring spinning reserve. The rationale behind this approach is that, according to economic theory, the equilibrium of energy-only markets in the long-term results in the optimal generation capacity, where scarcity payments to the marginal generators when demand exceeds supply covers exactly the cost of these generators [31]. The price hikes produced by the scarcity rents in the energy-only market are a signal for investment that should attract the right amount of generation capacity. Unfortunately, these price hikes are not only produced by the scarcity rent but also from some of the generating companies exerting market power. The price hikes can also be the result of anti-competitive bidding practices to raise the prices. In order to mitigate these prices hikes some regulators have placed caps on the market clearing prices.

However this approach has discouraged generating companies from making investments. To overcome this issue, regulators have introduced some incentives to promote capacity investment by providing generators the opportunities to get extra revenue. Most of the electricity markets in the Organization for Economic Co-operation and Development (OECD) countries rely on the energyonly market for capacity expansion [38].

\subsection{Capacity payment}

Capacity payment pays generators a per MW payment based on their availability whether they get dispatched or not [31]. Through this incentive, a GenCo has the opportunity to get extra revenue and is thus encouraged to invest in additional generation capacity.

The rationale to pay the generators for available spare MW comes from the theory of optimal capacity planning, which suggests that the marginal cost of incremental capacity should be equal to the marginal cost of unserved load. This can be approximated by multiplying the marginal VOLL with the probability that the load must be curtailed because of the capacity shortage (LOLP). The now defunct Electricity Pool of England and Wales used to make capacity payments at a rate proportional to the system's LOLP. The total capacity payment paid to a generator over a year is described by:

$$
\mathrm{CP}_{\mathrm{j}}=\sum_{\forall \mathrm{j} \in \mathrm{J}} \sum_{\mathrm{s}=1}^{\mathrm{S}} \text { VOLLXLOLPXFOR }_{\mathrm{j}} \mathrm{XP}_{\mathrm{j}}^{\max } \mathrm{Xd}_{\mathrm{s}}
$$

where VOLL is the system's value of lost load, $F O R_{j}$ is the forced outage rate of unit $j$ and $P_{j}^{\max }$ is the capacity of unit $j$. The VOLL which is the value that customers are willing to pay to avoid interruption should be determined based on customer surveys, but in this paper is assumed deterministic. On the other hand, the LOLP is calculated by first constructing a capacity on outage probability table (COPT) using recursive technique as shown in [39].

\subsection{Capacity market}

Some regulators set the amount of capacity available to meet a target value and let the market determine its price. This mechanism is known as capacity market.

In this paper the capacity market similar to that presented in [28] is used. The capacity market is assumed to take place on a yearly basis and the amount of capacity obligation is set by the system operator at a specified amount above the forecasted peak load. The market is designed to provide generating units that are neither dispatching energy nor procuring spinning reserve the opportunity to collect extra revenue for their unutilized generation capacity. Similar to the pool energy market, participants in the capacity market submit their bids, and those with the bid price below the clearing price are paid the market clearing price for the capacity offered. It is assumed that each generating unit that participates in the capacity market, bids at the following price, which is at the minimum price so that they do not incur any monetary loss.

$$
C M b_{m}=\left(\frac{A_{\text {revenue }, m}-A_{\text {prod_cost }, m}-A_{\text {investment }, m}}{P_{m}^{\max }}\right)
$$

where $A_{\text {revenue, } m}$ is the projected annual revenue of generating unit $m, A_{\text {prod_cost }, m}$ is the projected annual production cost and $A_{\text {investment, } m}$ is the present worth value of the initial investment which is uniformly annualized and 
amortized throughout the lifetime of the plant with the MARR. These are given as:

$$
\begin{aligned}
A_{\text {revenue }, m} & =\sum_{s=1}^{S} P_{m}^{\max } \times u f_{m} \times \pi_{\text {exp }, s} d_{s} \\
A_{\text {prod_cost }, m} & =P_{m}^{\max } \times M C b_{m} \times u f_{m} \times 8760 \\
A_{\text {investment }, m} & =I_{\text {PWV }}\left(\sum_{n=1}^{l t} \frac{1}{(1+M A R R)^{n}}\right)^{-1}
\end{aligned}
$$

where $u f_{m}$ is the utilization factor of generating unit $m, \pi_{\text {exp,s }}$ is the expected energy market clearing price at segment $s$, $M C b_{m}$ is the bidding cost of generating unit $m$ in the energy market, $l t$ is the lifetime of generating unit $m, 8760$ is the number of hours in a year and $I_{P W V}$ is the present worth value of the investment.

\section{Test Results}

The proposed model is tested on the IEEE Reliability Test System [39] omitting the hydro generation. The existing technologies in the system are listed in Table 1. It is assumed that there are three generating companies in the system and the portfolios are as follows: GenCo 1 owns the set of generating units $\{1-10\}$, GenCo 2 owns the set $\{11-20\}$ and GenCo 3 owns $\{21-26\}$. GenCo 1 owns primarily peaking generation, GenCo 2 owns the mid-field

Table 1. Existing units' technology and costs

\begin{tabular}{c|c|c|c|c|c|c}
\hline $\begin{array}{c}\text { Unit } \\
\text { Group }\end{array}$ & $\begin{array}{c}\text { Size, } \\
\text { MW }\end{array}$ & $\begin{array}{c}\text { Unit } \\
\text { Name }\end{array}$ & Unit type & $\begin{array}{c}\text { Heat rate } \\
\text { offset, } \\
\text { MBTU/h }\end{array}$ & $\begin{array}{c}\text { Heat rate, } \\
\text { MBTU/MWh }\end{array}$ & $\begin{array}{c}\text { Remaining } \\
\text { lifetime, } \\
\text { years }\end{array}$ \\
\hline U12 & $12 \times 5$ & $1-5$ & Oil/Steam & 2.81 & 3.07 & 15 \\
\hline U20 & $20 \times 4$ & $6-9$ & $\begin{array}{c}\text { Oil/Combus } \\
\text { tion turbine } \\
\text { (CT) }\end{array}$ & 13.87 & 4.49 & 10 \\
\hline U76 & $76 \times 4$ & $10-13$ & Coal/Steam & 44.38 & 8.82 & 17 \\
\hline U100 & $100 \times 3$ & $14-16$ & Oil/Steam & 24.03 & 2.23 & 8 \\
\hline U155 & $155 \times 4$ & $17-20$ & Coal/Steam & 64.88 & 7.28 & 14 \\
\hline U197 & $197 \times 3$ & $21-23$ & Oil/Steam & 26.59 & 2.81 & 15 \\
\hline U350 & $350 \times 1$ & 24 & Coal/Steam & 12.12 & 1.37 & 25 \\
\hline U400 & $400 \times 2$ & $25-26$ & Nuclear & 211.27 & 7.69 & 33 \\
\hline
\end{tabular}

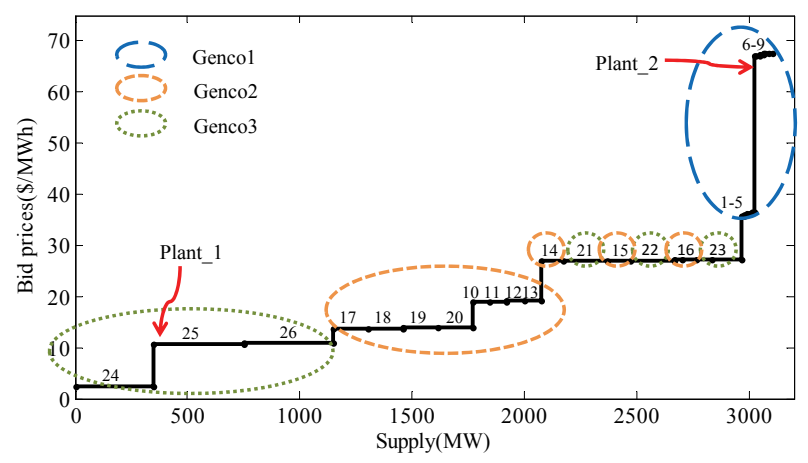

\begin{tabular}{|c|c|c|c|c|c|c|c|c|c|c|}
\hline $\begin{array}{c}\text { Plant } \\
\text { Name }\end{array}$ & $\begin{array}{l}\text { Size } \\
\text { MW }\end{array}$ & $\begin{array}{l}\text { Unit } \\
\text { type }\end{array}$ & FOR & $\begin{array}{l}\text { Util. } \\
\text { Factor }\end{array}$ & $\begin{array}{l}\text { Invest } \\
\$ / \mathrm{kW}\end{array}$ & $\begin{array}{c}\text { Heat rate } \\
\text { offset, } \\
\text { MBTU/h }\end{array}$ & $\begin{array}{c}\text { Heat rate, } \\
\text { MBTU/ } \\
\text { MWh }\end{array}$ & $\begin{array}{c}\text { MARR, } \\
\%\end{array}$ & $\mid \begin{array}{l}\text { Build } \\
\text { time, } \\
\text { years }\end{array}$ & $\begin{array}{l}\text { Lifetime } \\
\text { years }\end{array}$ \\
\hline Plant_1 & 250 & Coal & 0.08 & 0.9 & 2700 & 22.124 & 5.879 & 12 & 4 & 20 \\
\hline Plant_2 & 25 & \begin{tabular}{|l|} 
Oil \\
\end{tabular} & 0.02 & 0.1 & 900 & 3.011 & 4.821 & 12 & 2 & 20 \\
\hline
\end{tabular}

Fig. 3. GenCos' portfolios on the supply curve
Table 2. Technology and cost of the plants for investment

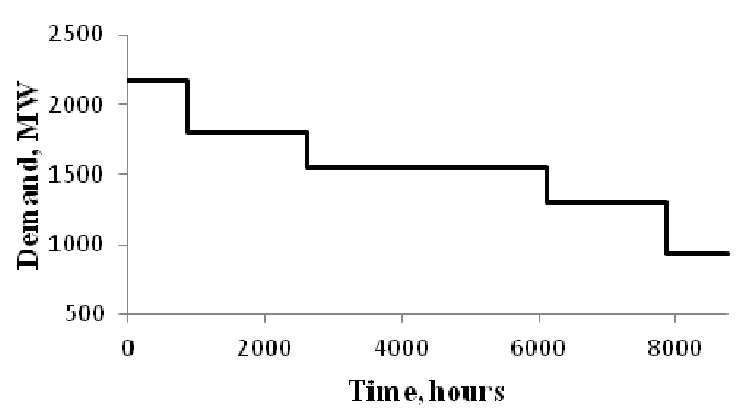

Fig. 4. Five segments of discretized LDC

generating units and GenCo 3 owns the base and some of the mid-field generation. Fig. 3 shows the supply curve for this system.

To facilitate analysis, each GenCo considers two plants for expansion every year i.e. Plant_1, a $250 \mathrm{MW}$ coal base plant and Plant 2, a $25 \mathrm{MW}$ oil peaking plant as shown in Table 2. The position of these plants on the supply curve according to their bid price is also shown in Fig. 3. Each GenCo expects that its competitors will also choose to invest in one of these plants.

The LDC has been discretized into 5 segments as shown in Fig. 4. The peak value is assumed to be $2173.5 \mathrm{MW}$ at year 0 and the magnitude of each segment of the LDC increases by $25^{*}(n-1)$ MW every year, where $n$ is the number of year. To consider uncertainty, the magnitude of each segment is modelled as a normally distributed random variable of amplitude $A_{s}=N\left(\mu_{s}, \sigma_{s}^{2}\right)$ and duration $d_{s}=$ $N\left(\mu_{d}, \sigma_{d}^{2}\right)$, where $\mu$ is the actual and $\sigma^{2}$ is the variance. The fuel costs are set at 2.31 \$/MBTU for coal, 13.5 \$/MBTU for oil and 5.54 \$/MBTU for gas. The system VOLL is assumed to be $2000 \$ / \mathrm{MWh}$. Since the demand is inelastic, the VOLL is also used as a cap in the energy-only markets. In the capacity market it is assumed that the installed capacity obligation passed to the load serving entities is $10 \%$ of the forecasted peak demand. All the existing generating units are considered sunk costs at year 0. For the competitors' expectation, each investment option on the scenario tree has equal probability to be selected. The simulation is performed for 12 years planning horizon.

The system has been tested in different case studies. In Case I, a study to validate that the model is capable of reacting to different scenarios that could trigger different degrees of investment, in Case II a case study in which the generating companies' strategic investment and generation expansion behavior in the energy-only market is analyzed, in Case III a study in which the generation expansion 


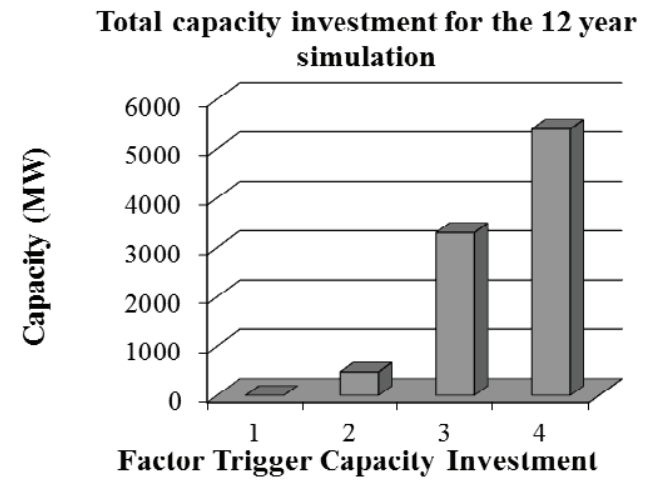

Fig. 5. Total capacity selected for investments over the 12 years for different scenarios

considering capacity payment and capacity market incentives are examined. Finally, Case IV presents a comparison between the incentives.

\subsection{Case 1: Various scenarios to trigger investment}

Four scenarios are considered over the 12 year planning horizon: 1) No load growth and no generation retirement, 2) No load growth with generation retirement, 3) $25 *(n-1)$ MW load growth on each segment of the LDC each year with generator retirement and 4) $40 *(n-1)$ MW load growth with generator retirement. These cases are chosen for a validation process to see how the model reacts to various scenarios that could trigger different degrees of investment. The simulations are performed for the energyonly market.

Fig. 5 shows the total capacity selected for investment over the 12 years planning horizon for each scenario. As one would expect, no generation is built when there is no load growth and no retirements. On the other hand, retirement only without load growth in the system triggers investments from the generating companies. As expected, larger investments arise when both load growth and retirement are taken into consideration in the simulation.

\subsection{Case 2: Dynamic investment in energy-only market}

Table 3 shows the new plant selected by each GenCo at each year over the 12 year planning horizon. The new plants are commissioned after the construction time has been completed as in Table 4. At the beginning of the simulation, none of the Gencos builds new generation; then as time goes by, and as the demand increases, the GenCos decide to invest in peaking (smaller unit) but these commissioned in years 3 to 5 , because of the time it takes for them to be built. Therefore as time goes by, the difference between installed capacity and system wide demand decreases until year 6. This happens because the capacity of these peaking plants is less than the growing demand. Fig. 6 shows this effect. This results in an increase
Table 3. New Plants Selected by the GenCos Each Year over the 12 Year Planning Horizon (1-Plant_1, 2Plant_2)

\begin{tabular}{c|c|c|c|c|c|c|c|c|c|c|c|c}
\hline Year & 1 & 2 & 3 & 4 & 5 & 6 & 7 & 8 & 9 & 10 & 11 & 12 \\
\hline GenCo 1 & None & 2 & 2 & 2 & 1 & 2 & 2 & 2 & 2 & 2 & 2 & 2 \\
GenCo 2 & None & 2 & 2 & 2 & 1 & 2 & 2 & 2 & 2 & 2 & 2 & 2 \\
GenCo 3 & None & 2 & 2 & 1 & 1 & 1 & 1 & 1 & 1 & 1 & 1 & 1 \\
\hline
\end{tabular}

Table 4. New Plants Get into the System Each Year over the 12 Year Planning Horizon (1-Plant_1, 2Plant_2)

\begin{tabular}{c|c|c|c|c|c|c|c|c|c|c|c|c}
\hline Year & 1 & 2 & 3 & 4 & 5 & 6 & 7 & 8 & 9 & 10 & 11 & 12 \\
\hline GenCo 1 & None & None & 2 & 2 & 2 & None & 2 & 1,2 & 2 & 2 & 2 & 2 \\
GenCo 2 & None & None & 2 & 2 & 2 & None & 2 & 1,2 & 2 & 2 & 2 & 2 \\
GenCo 3 & None & None & 2 & 2 & None & None & 1 & 1 & 1 & 1 & 1 & 1 \\
\hline
\end{tabular}

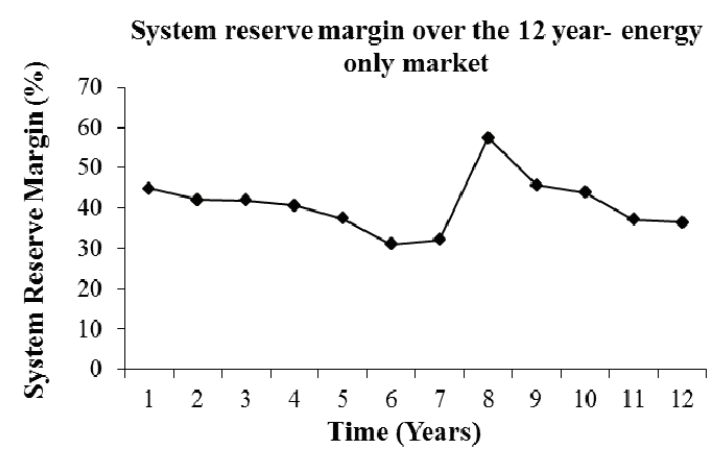

Fig. 6. System reserve margin over the 12 years planning horizon in the case of energy only market

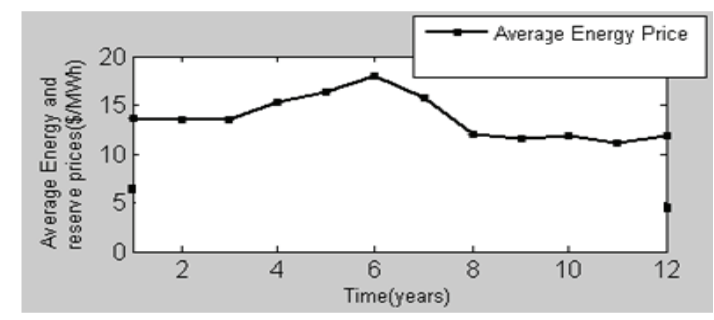

Fig. 7. Average energy over the 12 year planning horizon

in the energy prices until year 6 as shown in Fig. 7. These increasing prices are interpreted as a positive signal for investment by Genco 3, which chooses to invest in a larger plant (Plant_1) at year 4 followed by the remaining Gencos in year 5 . Since the base plant takes longer to be built, the reserve continues to fall to its lowest value in year 6 , which is also the peak point of energy price. The largest capacity commission occurs in year 8 when all the base plants selected by the GenCos in year 5 come online and cause the energy price to fall at its lowest price. It can be seen that the boom and bust cycle of the capacity investment appears in the energy-only market and this cycle continues over the remaining years.

In this market, since there is no incentive to encourage the Gencos to make investments, Genco 1 and Genco 2 
who own small and mid-size generators choose to build the peaking plants because building base plant would possibly turn their existing plants into extra-marginal units. On the other hand, Genco 3 who owns the biggest market share in the market continues to build the base plant to increase its profits. The results also prove that leaving the market without any form of regulatory intervention to promote generation expansion, should provide the correct incentives for capacity investment, but the system would undergo variations in the capacity margin, as well as energy prices on a cyclic basis.

\subsection{Case 3: Generation expansion with capacity payment}

Table 5 shows the new plants selected by the generating companies when they receive capacity payments. Under the capacity payments scheme, all the generating companies choose to build more base plants because this type of plant receives the larger revenues, since the payments are proportional to its capacity (see equation 10).

By offering capacity payment, the effect of the energy price has a smaller impact on the decisions to build generation. This effect can be seen in Fig. 8 when more new plants are added to the system during higher capacity payment and no plant is added between year 7 to year 9 when the payment is very low. The capacity payment is also proportional to the system's LOLP. When there is a large amount of capacity available relative to the load; then the system has a lower LOLP which in turn, reduces the capacity payment and thus discouraging further investments in generation. The opposite holds when there

Table 5. New Plant Selected by the Gencos in Capacity Payment over the 12 Year Horizon (1-Plant_1, 2Plant_2)

\begin{tabular}{c|c|c|c|c|c|c|c|c|c|c|c|c}
\hline Year & 1 & 2 & 3 & 4 & 5 & 6 & 7 & 8 & 9 & 10 & 11 & 12 \\
\hline GenCo1 & None & 2 & 2 & 1 & 1 & 1 & None & None & None & 1 & 1 & 1 \\
GenC02 & None & 2 & 2 & 1 & 1 & 1 & None & None & None & 1 & 1 & 1 \\
GenC03 & None & 2 & 2 & 1 & 1 & 2 & None & None & None & None & 1 & 1 \\
\hline
\end{tabular}

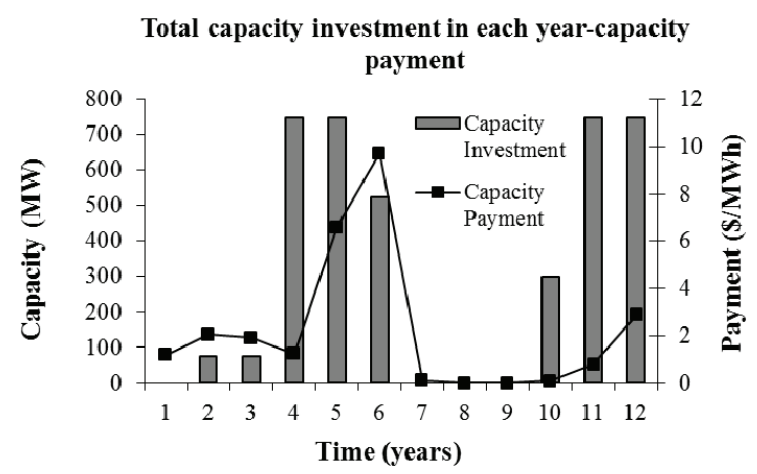

Fig. 8. Total capacity investment and capacity payment over the 12 year planning horizon

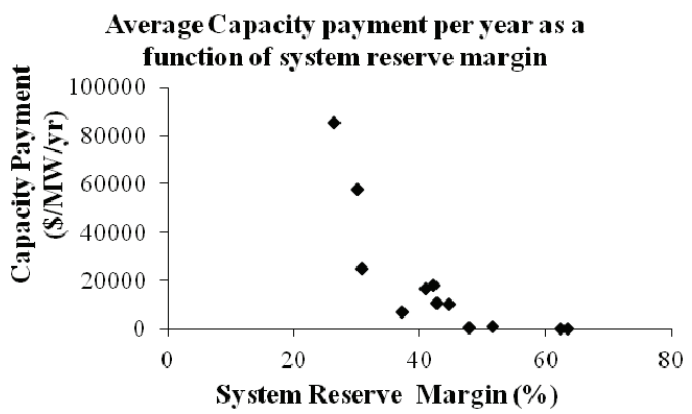

Fig. 9. Capacity payments as a function of reserve (\%)

is a small capacity margin in the system. The scatter plot in Fig. 9 shows that the capacity payment is exponentially reduced as the reserve in the system increases.

\subsection{Case 4: Generation expansion with capacity market}

The capacity market triggers investments to start from year 1 as shown in Table 6 . In the capacity market proposed in this paper, not all the generators can participate in the market to serve the capacity obligation. This additional market gives to the peaking units that are not dispatched in the energy market, the opportunity to collect revenue for their unutilized generation. This market thus, influences the investment choices of the GenCos. GenCo 1 tends to build more base plants to collect revenue from the energy market; meanwhile its existing peaking unit can still collect revenue by participating in the capacity market. On the other hand, GenCo 2 that owns mid-filed generating plants always gets dispatched in the energy market and building base plants would only displace its existing units in the supply curve. Because of this, GenCo 2 prefers to build peaking plants to collect extra revenue from the capacity market. Being the biggest base generation provider, GenCo 3 also chooses to accrue extra revenue from the capacity market by building peaking generation. By doing this also at the periods in which the peaking generation is required, the market clearing price increases, and thus its base units collect larger revenues in the energy market.

In this market, the profits received by the generating units are based on the clearing price of the capacity market, which is carried out on a yearly basis. These prices are also dependent on the available system reserve. When the reserve margin is low, because there in not sufficient spare capacity in the system, most of the generators need to be committed to produce energy, leaving the peaking generators available to participate in the capacity market, and thus to increase the capacity market clearing price. On the other hand, when the system has excess of generation capacity, fewer generators have the opportunity to produce energy; and they attempt to collect revenue by entering into the capacity market, resulting into lower clearing prices. The relative behavior between the reserve margin and capacity market prices is shown in Fig. 10. 
Table 6. New Plant Selected by the Gencos in Capacity Market over the 12 Year Horizon (1-Plant_1, 2Plant_2)

\begin{tabular}{c|c|c|c|c|c|c|c|c|c|c|c|c}
\hline Year & 1 & 2 & 3 & 4 & 5 & 6 & 7 & 8 & 9 & 10 & 11 & 12 \\
\hline GenCo1 & 2 & 2 & 2 & 1 & 1 & 1 & 1 & 1 & 1 & 1 & 1 & 1 \\
GenCo2 & 2 & 2 & 2 & 2 & 2 & 2 & 2 & 2 & 2 & 2 & 2 & 2 \\
GenC03 & 2 & 2 & 2 & 2 & 1 & 2 & 1 & 1 & 2 & 2 & 2 & 1 \\
\hline
\end{tabular}
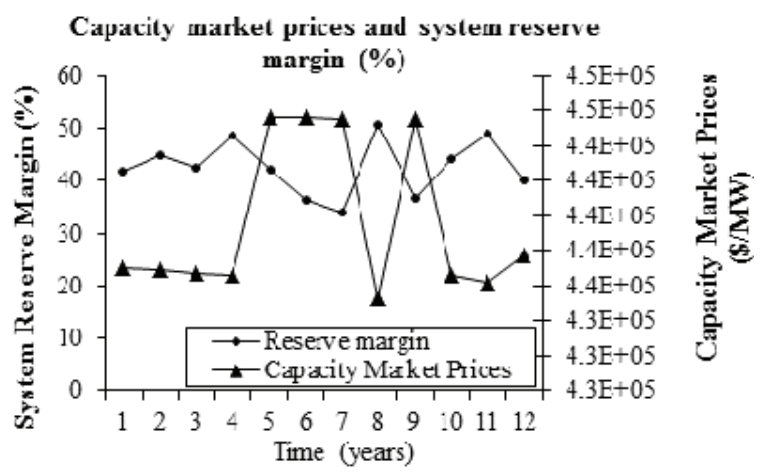

Fig. 10. Annual capacity market prices and reserve

\subsection{Case 5: Comparison of the different mechanisms}

Fig. 11 shows the total investment by the different GenCos for the 12 years planning horizon, under the different generation expansion mechanisms for a load growth of $25^{*}(n-1) \mathrm{MW}$ and $40 *(n-1)$ MW per year. Assuming that the market is competitive, the simulation shows that all the mechanisms succeed in promoting capacity investment in the system. Comparing the three incentive mechanisms, capacity payment is the one that results into the largest total investment for both load growth scenarios. This is followed by the capacity market and then by the energy-only market.

The simulation results show that all the mechanisms induce a similar pattern of boom and bust cycles. The amplitude of the cycles is a function of the capacity investments and the time between the booms and busts in each cycle vary between the mechanisms as shown in Fig. 12. It is seen that the capacity payment results in the largest swings of boom and bust as well as the biggest delay between the booms. This is because, the capacity payment is a function of the capacity made available, thus resulting to higher profits for those with larger amounts of spare capacity. These larger plants are able to cope with the load growth for longer, and thus delaying the price hikes that function as signals to the generating companies for the next investment boom. On the other hand, capacity market has the lowest amplitude and the most frequent of investment cycles. This is because, under this scheme, the GenCos tend to invest in the smaller units and cause the system reserve to drop faster in the next few years to cope with the system's load growth. The boom and bust cycle in the energy-only market is between the two mechanisms.

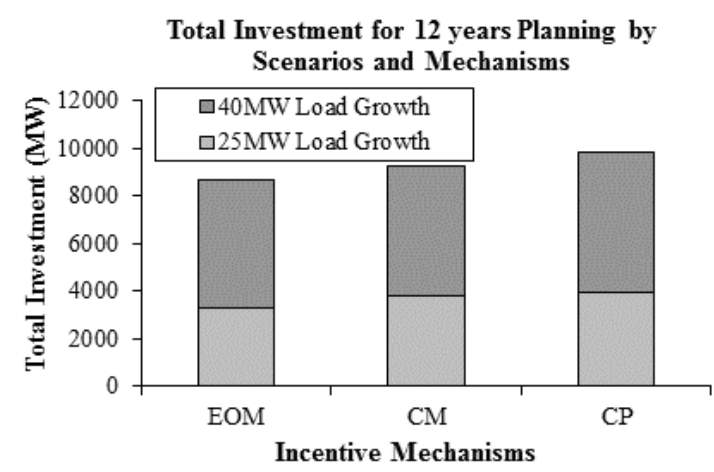

Fig. 11. Total investments for various scenarios and incentive mechanisms

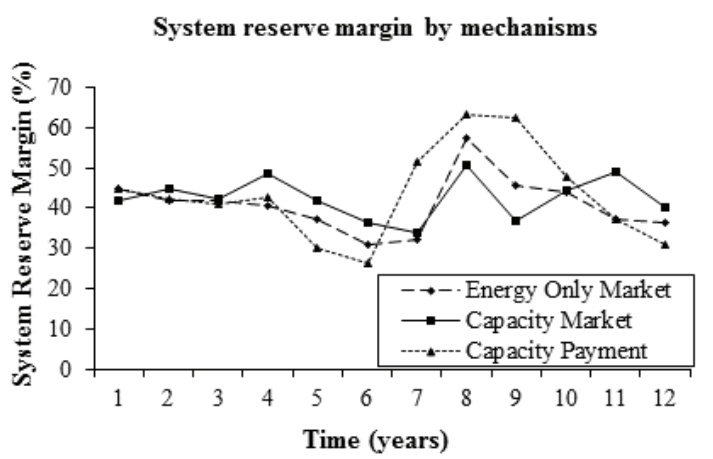

Fig. 12. Investment cycles over the 12 year planning horizon for various incentive mechanisms

\section{Conclusion}

This paper presents an agent-based model to study generation expansion in a restructured electricity supply industry. Assuming that the market is competitive, all the mechanisms succeed in promoting generation investment. It is seen that the 'boom' and 'bust' cycles also appear in the competitive market under all the capacity mechanisms. However the amplitude and the time delay of the cycles depend on how the mechanism is designed. The design of the capacity mechanisms also influence the investment decision of generating companies. This tool could be used by regulators to study generation expansion and to examine market designs. On the other hand, a GenCo could use this tool to understand the complexity of the electricity market and to generate various system expansion scenarios and to take the decisions that would result in a larger stream of revenues.

\section{Acknowledgement}

Our utmost gratitude goes to Malaysia Ministry of Education and Universiti Teknologi MARA (UiTM) who have sponsored this paper under Research Acculturation Grant Scheme (RAGS), 600-RMI/RAGS 5/3 (194/2014). 


\section{References}

[1] Angela S. Chuang, Felix Wu, Pravin Varaiya, "A Game-Theoretic Model for Generation Expansion Planning: Problem Formulation and Numerical Comparisons", IEEE Transactions on Power Systems, 16, 2001.

[2] F.H. Murphy, Yves Smeers, "Generation Capacity Expansion in Imperfectly Competitive Restructured Electricity Markets”, Operation Research, 53, 2002.

[3] Vishnu Nanduri, T.K. Das, "Game Theoretic Approach for Generation Capacity Expansion in Restructured Power Markets",PES General Meeting Pittsburgh, 2008.

[4] Efraim Centeno, Javier Renesas, Sonja Wogrin, Julian Barquin, "Representation of Electricity Generation Capacity Expansion by Means of Game Theory Models", 8th International Conference on the European Energy Market (EEM), 2011.

[5] A.A. Ladjici, M. Boudour, "Nash-Cournot Equilibrium of a Deregulated Electricity Market Using Competitive Coevolutionary Algorithms", Electric Power Systems Research, 81, 2011.

[6] Cristian A. Diaz, Jose Villa, Fco. Alberto Campos, M. Angel Rodriguez, "A New Algorithm to Compute Conjectured Suppply Function Equilibrium”, Electricity Markets, Electric Power System Research, 81, 2011.

[7] Damoun Langary, Nasser Sadati, Ali Mohammad Ranjbar, "Direct Approach in Computing Robust Nash Strategies for Generating Companies in Electricity Markets", International Journal of Electrical Power \& Energy Systems, 54, 2014.

[8] Prajit K. Dutta, "Strategies and Games: Theory and Practice", The MIT Press, 1999.

[9] Ing. D. Juan Jose Sanchez Dominguez, "Strategic Analysis of the Long-Term Planning of Electric Generation Capacity in Liberalized Electricity Markets", Instituto de Investigacion Tecnologica, Universidad Pontificia Comillas De Madrid, Madrid, 2008.

[10] A. Botterud, "Long Term Planning in Restructured Power Systems, Department of Electrical Power Engineering", The Norwegian University of Science and Technology (NTNU), 2003.

[11] E. Alishahi, M. Parsa Moghaddam, E. Alishahi, M.K. Sheikh-El_Eslami, "A System Synamics Approach for Evaluating the Optimum Value of ReliabilityBased Incentive Mechanism for Wind Generation in GEP", Power Engineering Society, PES General Meeting 2012.

[12] A. Ford, "Cycles in Competitive Electricity Markets: A Simulation Study of the Western United States", Energy Policy, 27, 1999.

[13] A. Ford, "Waiting for the Boom: A Simulation Study of Power Plant Construction in California", Energy Policy, 29, 2001.
[14] John Bower, Derek Bunn, "A Model-Based Comparison of Pool and Bilateral Market Mechanisms for Electricity Trading”, Energy Journal, 21, 2000.

[15] Derek W.Bunn, Fernando S.Oliveira, "Agent-Based Simulation-An Application to the New Electricity Trading Arrangements of England and Wales", IEEE Transactions on Evolutionary Computation, 2001.

[16] D.W. Bunn, M. Martoccia., "Unilateral and Collusive Market Power in the Electricity Pool of England and Wales", Journal of Energy Economics, 27, 2005.

[17] M. Mahvi, M.M.Ardehali, "Optimal Bidding Strategy in a Competitive Electricity Market Based on AgentBased Approach and Numerical Sensitivity Analysis", Energy, 36, 2011.

[18] Zhen Liu, Jianming Yan, Kaiwei Zhu, Gangqing Pu, "Multi-agent Based Experimental Analysis on Bidding Mechanism in Electricity Auction Markets", International Journal of Electrical Power \& Energy Systems, 43, 2012.

[19] T. Pinto, H.Morais, P. Oliveira, Z. Vale, I. Praca, C. Ramos, "A New Approach for Multi-agent Coalition Formation and Management in the Scope of Electricity Markets", Energy, 36, 2011

[20] S. Widergren, J.Sun, L. Tesfatsion, "Market Design Test Environment", IEEE PES General Meeting 2006.

[21] Thomas Veselka, Gale Boyd, Guenter Conzelmann, Vladimir Koritarov, Charles Macal, Michael North, Benjamin Schoepfle, Prakash Thimmapuram, "Simulating the Behavior of Electricity Market with an Agent-Based Methodology: The Electric Market Complex Adaptive System (EMCAS) Model", Proceedings of the 22nd Annual Conference, 2002.

[22] Isabel Praça, Carlos Ramos, Zita Vale, "MASCEM: A Multiagent System that Simulates Competitive Electricity Market", IEEE Transactions Intelligent System, 18, 2003.

[23] Anthony J.Bagnall, George D. Smith, "Game Playing with Autonomous Adaptive Agents in a Simplified Economic Model of the UK Market in Electricity Generation”, Power System Technology, 2000.

[24] Anthony J.Bagnall, George D. Smith, "A Multiagent Model of the UK Market in Electricity Generation", IEEE Transaction on Evolutionary Computation, 2005.

[25] Gong Li, Jing Shi, "Agent-Based Modeling for Trading Wind Power with Uncertainty in the Dayahead Wholesale Electricity Markets of Single-sided Auctions", Applied Energy, 99, 2012.

[26] Zhi Zhou, Fei Zhao, "Agent-Based Electricity Market Simulation With Demand Response from Commercial Buildings", IEEE Transaction on Smart Grid, 2, 2011.

[27] Audun Botterud, Matthew R.Mahalik, Thomas D. Veselka, Heon-Su Ryu, Ki-Won Sohn, "Multi-Agent Simulation of Generation Expansion in Electricity Market”, PES General Meeting, IEEE, 2007. 
[28] Miguel A. Ortega-Vazquez, DS Kirschen, "Assessment of Generation Expansion Mechanisms using Multi-Agent Systems", PES General Meeting, 2008.

[29] Edgard Gnansounou, Jun Dong, Samuel Pierre, Alejandro Quintero, "Market Oriented Planning of Power Generation Expansion Using Agent-Based Model", Power System Conference and Exposition, IEEE PES, 2004.

[30] Charles M. Macal, Michael J.North, "Tutorial on Agent-Based Modeling and Simulation Part 2: How to Model with Agents", Proceedings of the 2006 Winter Simulation Conference, 2006.

[31] Shmuel S. Oren, "Ensuring Generation Adequacy in Competitive Electricity Markets", University of California, 2003.

[32] Robert Stoddard, Seabron Adamson, "Comparing Capacity Market and Payment Designs for Ensuring Supply Adequacy", 42nd Hawaii International Conference on System Sciences, 2009.

[33] Peter Cramton, Steven Stoft, "A Capacity Market that Makes Sense”, Electricity Journal, 18, 2005

[34] Derek W. Bunn, Erik R.Larsen, "Sensitivity of Reserve Margin to Factors Influencing Investment Behaviour in the Electricity Market of England and Wales", Energy Policy, 20, 1992.

[35] Choong-Kyo Han, Don hur, Jin-Man Sohn, JongKeun Park, "Assessing the Impacts of Capacity Mechanisms on Generation Adequacy with Dynamic Simulations", IEEE Transactions on Power Systems, 201.

[36] Ming-Che Hu, Benjamin F. Hobbs, "Dynamic Analysis of Demand Curve Adjustment and Learning in Response to Generation Capacity Cost Dynamics in the PJM Capacity Market", PES General Meeting, 2008.

[37] Benjamin F. Hobbs, Ming-Che Hu, Javier G. Iñón, Steven E. Stoft, Murty P. Bhavaraju, "A Dynamic Analysis of a Demand Curve-Based Capacity Market Proposal: The PJM Reliability Pricing Model", IEEE Trans. Power System, 22, 2007.

[38] International Energy Agency (IEA), Security of Supply in Electricity Markets: Evidence and Policy Issues, Organization for Economic Co-operation and Development (OECD), 2002.

[39] R.N.A. Roy Billinton, "Reliability Evaluation of Power Systems”, Springer, 1994.

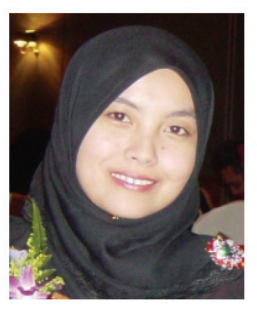

Nofri Yenita Dahlan She received electrical degree, B. Eng (Hons) from Universiti Tenaga National (UNITEN), in 2001, M.Sc. degree from the University of Manchester Institute of Science and Technology (UMIST), in 2003, and Ph.D. degree from the University of Manchester, Manchester, U.K., in 2011. She has been awarded a Certified Measurement and Verification Professional (CMVP) in year 2013. 